\title{
Technology Initiatives: A Shared Leadership of Digital Natives and Digital Immigrants
}

\author{
Anna Lissa Miranda Gonzales, Hernando Lintag Bernal Jr, Juan Miguel Ramos Reyes, \\ Jeffrey Ramos Reyes, Mariel Mignon Ortega Tan
}

General Education Department, Far Eastern University-NRMF, Quezon City, Philippines

Email address:

Annalisagonzales@yahoo.com(A. L. M. Gonzales),bhambernal@gmail.com(H. L. Bernal Jr), migsrreyes@gmail.com(J. M. R. Reyes), jjrmsrys@gmail.com(J.R. Reyes),marielmignon@gmail.com (M.M. O. Tan)

\section{To cite this article:}

Anna Lissa Miranda Gonzales, Hernando Lintag Bernal Jr, Juan Miguel Ramos Reyes, Jeffrey Ramos Reyes, Mariel Mignon Ortega Tan. Technology Initiatives: A Shared Leadership of Digital Natives and Digital Immigrants. Higher Education Research.

Vol. 3, No. 4, 2018, pp. 66-74. doi: 10.11648/j.her.20180304.12

Received: October 6, 2018; Accepted: November 21, 2018; Published: December 26, 2018

\begin{abstract}
This study was designed to determine the leadership practices on technology initiatives for allied programs in medicine and utilization. It utilized descriptive - correlational method of research. Methods include teachers and students who were being interviewed. With the use of qualitative analysis, results show that shared leadership, organizational condition, staff support, and media and software are common to the teachers and learners in terms of digital natives. It also shows the impact of the leadership practices in relation to managing technology initiative. It is found out that relationship between leadership practices and its impact on the implementation and utilization of technology initiative has no significant relationship. It could be possible that administrators' leadership focuses on relevant, timely, and regular professional development of teachers that are anchored on the school's vision/mission which may lead to uplift the school's academic standard in general and enhancement of students' learning in particular. Educational leaders' investment on human and technological resources may increase the school's chance of gaining stakeholders' support that may eventually lead to increase in enrolment. Students who are satisfied with the technological services being provided by the school may serve as its campaign arm to encourage more enrollees in the future.
\end{abstract}

Keywords: Healthcare, Leadership, Technology

\section{Introduction}

Technology is in a constant state of change with technological innovations emerging daily [1]. With technology comes a leader of educational technology who has to be flexible in this changing environment. In an everchanging technology environment, leadership is deemed important by presenting a vision, communicating the vision and integrating that technology into classroom instruction. In addition, leadership instruction ensures different types of resources which are accessible for the learners and teachers to access for the emerging technologies. Instruction and curriculum must be considered the driver and technology is simply the vehicle.

In any school change effort, the functions assumed by the administrator through each phase of implementation is critical in the field of leadership. The attitudes and actions of school administrators surrounding new technologies encourage and support faculty as they are engrossed in learning opportunities and in exploring new tools.

It is important that there are other ways to classify people aside from age, and that would be with the use of technologies, i.e., modern technologies [2]. They find themselves being called to decide complicated human and technical issues. In this regard, they are increasingly identifying themselves as learners, continuously searching the environment for innovations and solutions.

Technological leadership initiative requires an understanding of transformation. Education should be conscious of the social and emotional needs of its workers. The leader has to face with disagreements and negative emotions because these can affect the smooth flow of any technological initiatives and the pleasant relationship existing 
between them. Pleasant relationship may also happen between workers if they have an open communication [3].

The framework of this study was primarily anchored on Theory of Digital Natives [4]. This theory expounded that in the 21 st century, learning could be more natural and fluid where students are not going to necessarily be working in regimented factories where they need structure and discipline. They are going to be exposed in the environment finding solutions to problems and applying all disciplines at once. It is therefore crucial that educational institutions apply technology to enhance the capabilities of an interdisciplinary unit and further permit the learners to dwell on the "Future" content that mirrors the 21 st century. He also suggested that since the present period is a technological world and one's daily actions are performed with computers or some other form of technology, it would be negligence of educational institutions not to include technology tools into their curriculums.

The 21st century has seen an influx of technological mechanisms, and those born into this age are termed digital natives because they are native speakers of the digital language of computers, video games, and the internet. For the digital native learner, the computer language and technology is innate and considered as an alternative language. Technology has set 'spatial boundaries which is at the level of undifferentiated and freely accessed opportunities [5]. This could be possible as the digital natives have been speaking in different language of technology. These digital natives are considered to be the generation of young people born in the digital age and are considered to be techno-savvy [6].

There was a reiteration [4] that educators must continue their professional development gearing toward enhancement of their instruction, planning, and enhancement of their performance. Educators must likewise use technology tools in the school for the digital native learner even if this use will influence their performance because the infusion and technological utilization in the classroom helps to engage and inspire the students. Failure to consider technology in the curriculum may decrease the engagement and relevant lessons may have for digital native students. If these digital natives fail, there is considered to be also a 'digital wisdom' which could be used for relations on electronic communication, higher education and elite culture [7]. Collaboration is also essential as with the teachers and the students in terms of technology. There are potential important contributions to transfer and develop complexities for the existing technologies and policies for designs [8].

Sequence should also follow an emergence of complex adaptive systems which involves local to global scales. There might be barriers involved in terms of innovation, however, invention of technology should go through the selection, production, adaptation, adoption, and retirement, if there is such a thing as that in technology [9]. The young adults look for and evaluate Web contents as there are users who work online with credibility assessment through which people encounter [10].

This paper was conceptualized to find the current leadership practice of administrators regarding their technological initiatives being introduced by teachers to their students. This study involved the appraisal of the current technology initiatives and teachers' utilization and determination of the evident leadership practices and its influence to the completion of the technology initiatives. The findings primarily employed the articulation of sustainable leadership and instructional framework that may be advantageous to institutions of higher education in general and students in particular.

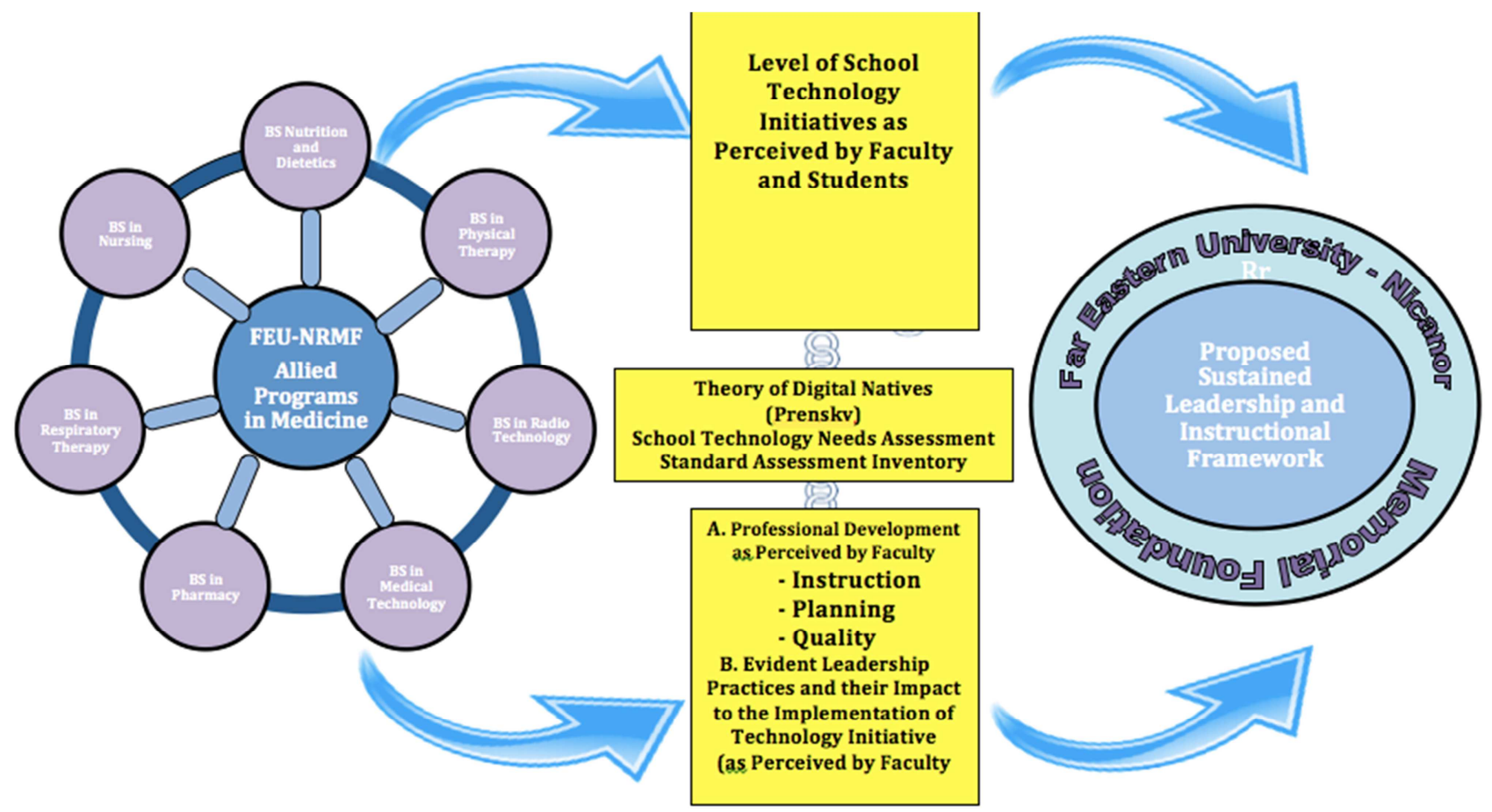

Figure 1. Research paradigm. 
This research study aims to answer the following questions:

1. What leadership practices were evident in the utilization and implementation of technology initiative among faculty and students?

2. To what extent does each leadership practice impact the implementation of technology initiative and its utilization?

3. Is there a significant relationship between the leadership practices and its impact on the utilization and implementation of technology initiative?

4. What sustainable leadership and instructional framework can be recommended based on the results of the study?

In a brief article "Understanding Design", it explained how important curriculum is in the selection of media and software [4]. He stated that schools might find themselves stuck in a variety of initial implementation efforts, trying one thing after another, and not achieving full implementation of a program because of failure to scrutinize the intended curriculum.

\section{Methodology}

This part of the research presents the research design, procedure, and instruments used in the study.

\subsection{Research Design}

This study uses the descriptive approach. It covers the present technology initiatives being implemented by teachers of FEU-NRMF and the college Deans' leadership practices towards these initiatives. The extent of these leadership practices to the technology initiatives is also part of this study.

\subsection{Procedure}

The respondents in this research were specific to the students and faculty of the various allied courses in Medicine of Far Eastern University-Nicanor Reyes Medical Foundation.

Total enumeration was utilized in terms of facultyrespondents. Slovin's formula for sample size approximation was employed to determine the student sample size. Since student participants were divided into seven allied courses, stratified sampling was used to determine the number of respondents that would represent each course. To apply this sampling procedure, the researcher first secured the population of enrollees per course from second year to fourth year. The required number of student-respondents based from slovin's formula was then used to subdivide the student population.

\subsection{Instruments}

As regards technology innovation, this study used the modified standard survey assessment developed from the framework of Prensky's Theory of Digital Natives [4]. It is used as a conceptual model to understand how leaders or supervisors apply the modernization in their leadership practices by optimization on the delivery of the basic education service. Modification and re-validation of the survey tool was initiated to make certain that it would fit the research setting.

For the evident leadership practices of School Deans, SAI checklist on leadership practices for District School [3] was utilized.

The researchers surveyed the available standard questionnaires relative to this study. The information obtained out of reading books, journals, theses, dissertations, and consultations with colleagues and professors were all considered in the assortment of the best-standardized tool. The selected standardized tool was presented to advisers for comments, suggestions, and approval. The only parts that were retained from the original tool were those that covered areas on vision and shared leadership, flexible scheduling, infrastructure, staff support, and media and software.

The outline of the survey tool was validated by a group of experts. After some modifications and corrections, the final outline was developed and reproduced. A pilot test was conducted to 20 faculty members and 150 students who were not involved as respondents to establish the validity and reliability of all items.

A permit to conduct casual interview with the students and selected teacher-participants was sought. This was accomplished during the respondents' most convenient time so as not to hamper their respective schedules. The focus of the interview was more of following up of the consequences of their replies to the questionnaires. The interview was initiated to get additional information that may not be obtained directly through surveys and questionnaires.

\section{Results and Discussion}

The following are the answers to the research questions of this study.

\subsection{Leadership Practices in the Utilization and Implementation of Technology Among Faculty and Students}

\subsubsection{Vision and Shared Leadership}

The appraisal of the faculty and students on the status of technology initiative and utilization for allied programs in Medicine in terms of vision and shared leadership. It is evident that the development on the foresight for technology through efficient partnership among stakeholders was always observed by the teacher respondents and received the highest weighted mean of 4.53. It is followed by the administrators' support on revolutions in school level systems, guidelines, and practices connected to technology that was observed most of the time with a weighted mean of 4.37 . The least 
among the given indicators that was also observed most of the time was on material incentives received by the teachers out of using technology in the classroom. The faculty participants in this study observed all other indicators most of the time.

Results therefore imply that the administrators, from the President of the university down to different department heads realized how important technological advancement is regardless of the course of study. Faculty-participants from the school of nursing, physical therapy, medical laboratory science, respiratory therapy, and radiologic therapy supported this claim and even said that there is a certain level of technology initiatives and innovations being integrated in the practice of vision and shared leadership. One proof of such is the ongoing provisions to increase supplies of technological materials such as projector, TV monitors, and computers in all departments. Although the top-down approach of leadership is manifested in the participating school, respective deans and department heads of different colleges are still given the authority to initiate plans and programs in line with technological advances of their particular departments.

From the given indicators, it can be observed that teachers, being the technology innovators were not assumed material incentives in a very satisfactory manner. Material incentives may include earnings, benefits, waivers, and other special opportunities like travel incentives. Some faculty participants from the College of Pharmacy expressed that they seldom receive any material incentives over their effort to utilize technology innovation in their teaching. However, other respondents of the same course attributed this lack of incentives to the point that the college of pharmacy is one of the youngest college established at FEU-NRMF. In general, the absence of all these rewards were not considered a big issue for other faculty.

On the part of the student participants, all the indicators about the vision and shared leadership on technology were observed most of the time. Results manifest that vision for technology developed through an effective collaboration among stakeholders obtained the highest weighted mean of 4.32. It is followed by the administrators' effective implementation on the uses of technology with a weighted mean of 4.24. The least among the indicators was on the teachers' technological literacy and innovators in their own subject matter with a weighted mean of 4.01 . These findings clearly show that students are quite pleased with the technological initiatives and innovations being integrated in the exercise of vision and shared leadership. The student government president in the seven allied medical courses appreciated the administrators' huge apprehension over the functions that technology plays in their respective courses. They also disclosed their participation on consultation meeting that concerns the university's proposal of action to enhance the standard of instructions in different colleges. Student participants particularly on the college of pharmacy, one of the new courses offered in the university, expressed also their contentment on the attribute of technological services being presented by the university. Although equipment was not absolutely enough for the increasing population of the college, the basic and the most needed ones were provided for the college's use.

The above stated findings for learners when they expressed that technology is in a constant state of change with new innovations emerging daily supported faculty respondents. Educational leaders should have a wide vision for technology and should invest much on it. Just as technology has modified aspects of one's daily lives, it is undoubtedly changing education. Innovations on technology make it probable for easy access to information, but the communication established by students remain the same.

\subsubsection{Organizational Conditions}

Organizational Conditions displays the faculty and the students' assessment on the status of technology initiative and utilization of allied programs in Medicine in terms of organizational conditions.

Viewed from the responses of the faculty, technology is used most of the time to communicate and collaborate with the community and the families about school programs designed to enhance student learning. These indicators received the highest weighted means of 4.19 and 4.06 respectively The issues on insufficient budget relative to implementing decisions arising from planning and continuous updating and replacing outdated technology systems were sometimes observed and these obtained the lowest weighted means of 3.34 and 3.4 respectively. All other indicators were rated most of the time.

The results proved that FEU-NRMF considers technology as the fastest and easiest way of disseminating information about activities and platforms to the students, parents, community, and other shareholders. Faculty respondents particularly in the college of Medical Laboratory Science, Physical Therapy, and Nursing confided that the partners of the Board of Trustees including their deans were very determined to use technology to the maximum in all colleges and departments. The existing organizational conditions relative to technology were given priority so that plans for improvement shall be put into action the soonest possible time. The research participants identified some notable manifestations of technology improvements in the campus in general and different allied courses in particular. These comprises the fully automated enrolment system, electronic encoding and release of grades, regular updating of the campus websites, and continuous acquisition of technological equipment for use of different departments. The college of Medical Laboratory Science and Physical Therapy deans, two of the existing old courses in the university disclosed that the rapid proliferation of medical schools has been perceived nowadays. FEU-NRMF, being the pioneer school in the 
field of medicine should then find ways and means to make the program of the institution unique and competitive to invite more enrollees. Updating and procurement of the very sophisticated equipment in the field of medicine may be considered the best choice university at par with highest technological standard. Other departments also do its monitoring and updating of technology plan at most twice a year. Research participants from other allied courses also do their share by supporting whatever technology plans and programs that their respective departments have for enhancement of learning.

On the part of the student participants, all the indicators stated under Organizational Conditions were observed most of the time. The expansion of the school technology proposal of the students, parents, and community, together with the officials, consultants, teachers, and municipal members received the highest weighted mean of 4.03 . This is followed by the use of technology to connect with the community about school platforms and student learning with a weighted mean of 3.96. Multiple sources of data used to assess the influence of technology initiatives on student education and the availability of budget to update and replace outdated technology systems garnered the lowest weighted means of 3.69 and 3.82 respectively.

Technology indeed plays a dynamic role in information dissemination and communication. The internet's availability in the educational institution and even in every household and establishment facilitates and speeds up communication among people. Such technological innovations made it conceivable for the educational institution to disseminate school programs to concerned entities for a short span of time. Student respondents particularly the researcher's college students of medical science and radio technology confided that the online enrolment and electronic checking of grades have brought them much convenience. Gone were the days where students would have to fall in line just to be enrolled in their respective colleges and then waited for so long to receive the final grades issued personally to them.

With regards to program implementation, one common problem encountered by any implementing institution is the budget. Of all the seven allied medical courses, the college of Radio Technology respondents raised the issue on insufficient budget allotted for the department's technology program. Radio technology equipment like $\mathrm{x}$ ray machine needs to be upgraded. On the part of the dean of the college, she disclosed that few enrolment of the college has become an issue in the upgrading of equipment. The university cannot provide instantly all the needed facilities and equipment unless the urgency is felt. However, the school has already prepared its program to update the department's technological equipment beginning school year 2017-2018. Faculty respondents from the college of Nutrition and Dietetics also raised the issue on the department's pending request for procurement of additional equipment of the department particularly the
Body Composition Analysis Machine in the school year 2016-2017. On the part of the Department head who happened to be a respondent, too, of this research, budget for the much needed technological equipment has been allotted and the department remains positive that the needed equipment would be made accessible on school year 2017-2018.

\subsubsection{Staff Support}

The faculty and students' assessment on the position of technology initiative and utilization for allied programs in medicine in terms of staff support were observed most of the time by both faculty and student respondents. The occurrence of library media coordinator and media assistants gained the highest weighted mean of 4.24 for faculty while the adequacy of technology facilitator and technology assistant got a 4.0 weighted mean for the students.

It can be inferred that the faculty of the seven allied medical courses are generally satisfied on the technical support and manpower being provided by the school. The university's media center assigned specific personnel to different colleges to monitor, maintain systems, and troubleshoot problems on software and hardware. The deans of the college of nursing, physical therapy, and medical laboratory science reiterated the significance of providing training on basic technology trouble shooting to all faculty members. This program would surely help lessen the call for any staff support should technical problems arise in their teaching. Furthermore, the deans also emphasized the magnitude of special skills is for technology teachers particularly on basic troubleshooting. Teacher -applicants who possessed such skills and those with crash course in computer technology were more preferred to be hired by the university.

However, it was so surprising that among the allied medical courses, the faculty participants from the college of Nutrition and Dietetics generally expressed their sentiments on the lavishness of technical support being extended to them. Some disclosed that it took a number of days before the technical personnel acted on their request for repair of computer units and troubleshooting of viruses and bugs.

The deans of the college of Respiratory Therapy and radio technology highlighted the significance of monthly preventive maintenance check up of all the technological equipment accessible in distinctive colleges. Such action would give the technical staff to avoid crushing of the units while on use.

For the student participants, it can be clinched that technological personnel are always available and willing to assist students should they need assistance particularly on the operation of technology equipment. The researcher, being a faculty associate of the university also observed the competencies of all the technology staff. Some of them were computer-engineering graduates in custody of delivering technical support to the students. Some were computer science graduates and other computer related courses. Student participants from the seven allied courses 
also expressed their satisfaction in terms of the capabilities of all the technical staff. They also disclosed that majority of these support staff were also their professors in computer subjects.

\subsubsection{Media and Software}

The faculty and students' assessment on the status of technology initiative and utilization for allied programs in medicine in terms of media and software were observed most of the time by both faculty and student respondents. Consideration of the curriculum and needs of learners in the choice of media and software acquired the highest weighted mean of 4.21 by the faculty members. This is followed by the ready access to productivity software by teachers and students with weighted mean of 4.10 .

Data from this research clearly manifest the prominence of the curriculum and students' needs in the choice and procurement of media and software. ICT faculty from different allied medicine courses exposed the significance of studying the existing university curriculum before engaging into the selection of the technology software to be used. Different courses have varying technological needs. In order to extend the use of the software, series of consultation with the deans of different colleges is required to reconcile whatever problems are noted in the curriculum. Moreover, the price of the licensed software has to be considered, too, since in a big university like FEU-NRMF, the use of cracked software has never been tried. Faculty from the college of respiratory therapy, nursing, and pharmacy were very vocal to express their gratefulness to the university board for providing their respective departments the needed technological software proposed for use by the faculty and students.

Each classroom is equipped with the needed educational technology devices, teachers and students already have direct entry to all these equipment. The university librarian who happened to be a faculty participant in this research also extended her gratitude to the university for providing the library a complete set of software and media for the practice of the learners.

On the student participants' side, the consideration of the curriculum and the learners' needs in the choice of resource media center received the highest weighted mean of 3.94. The same value of the weighted mean was also obtained by the teachers' ready entry to a cataloging system used for examining and locating teaching. Following with a close margin are the last two indicators on teachers and students' access to productivity software and collection of print, multimedia, and electronic capitals that both received a weighted mean of 3.90 .

Both the curriculum and basics of learners were the topmost priorities in the choice of resource media and software. Although the President of the university with the Board of Trustees and Heads of different allied courses are the ones determining the kind of technology package to be given to each department and the students the right to use the technology equipment in the different departments.
For the Radio technology students, they expressed their appreciation on the gesture of support being provided to them by the university. Despite being one of the new courses offered in the university, the laboratory is equipped with the necessary technology equipment like x-ray equipment, $x$-ray tube, beam restrictors and the like.

The students from the college of Nutrition and Dietetics revealed a need to prepare a wide space and fully equipped domestic scale teaching kitchen with several work stations that can accommodate a huge number of students. The population of the department continuously grows and therefore would need a spacious laboratory.

Students from other departments did not express any discontentment on the technology equipment and software available in their own departments. However, they would appreciate very much if the university could provide more resource equipment for use in the laboratory.

As regards students' access to productivity software, since each classroom is equipped with the basic technology devices, the professors were the ones preparing the materials to be utilized in the activity. If no licensed software would be available in the school, professors were sometimes the ones providing for such.

For the university, the deans of the college of Radio technology, Respiratory Therapy, and Nutrition and Dietetics confided to the researcher that they are continuously planning for upgrading of the school's technology equipment. However, not all plans could be put into action because of the budgetary problems.

Technological advances through proliferation of different media and software provide easier facilitation of and access to information, but the message received by students remains the same, or the students' ability to grasp and retain information.

\subsection{Extent of Leadership Practice in the Implementation of Technology Initiative Among Faculty and Students}

It can be observed that leadership practices on all of the areas assessed were most evident as indicated by the overall average weighted mean of 3.87. Among the areas assessed, highest weighted mean of 3.94 was observed in terms of the following: School Goals Mission/Vision, instructional practice, focus on student improvement, timely, relevant and ongoing professional development, while the lowest was observed to be in terms of collaborative decision making with a weighted mean of 3.68 .

Results can be ascribed to the fact that there are areas of leadership practice where the use of technology is needed for efficient implementation, employee/faculty empowerment and achievement of learning. This further implies that educational leaders of FEU-NRMF promote the balanced technology integration to assist in improving student learning, faculty empowerment, and efficient educational policy implementation. 


\subsection{Impact of Leadership Practices in Relation to Managing Technology Initiatives}

It was revealed that the faculty in general recognizes the very great impact of leadership practices in the implementation and utilization of technology initiatives and utilization in the institution as indicated by an overall weighted mean of 3.61. The faculty further stressed that being an empowering leader (3.75) has the greatest impact among the evident leadership practices of the Deans. This indicates the eagerness of the faculty to be given all the support and the chance to utilize technology in their work. The leadership practices was also found to have very great impact on the schools' goals, mission and vision (3.69) and the very great impact of the leadership practice in the allocation of resources (3.68). These top 3 responses of the faculty further reveal their eagerness to cope with the international challenge of meeting the demands of the $21^{\text {st }}$ century learners. This can be ascribed to the fact that technology initiatives and utilization in FEU-NRMF just like other institutions have loopholes that should be addressed. Though the faculty believes evident leadership practice exist in the implementation, discrepancy in the implementation itself obvious as indicated by the weighted means obtained. This was supported by Price et al (2012) stating that this discrepancy maybe due discomfort with using technology in instruction. While students are exposed to computers in the classroom or school facilities were provided for such need, the use is only for gathering of information rather than frequently using multimedia tools to design and create products.

On the part of the faculty, they believed that leadership practice has moderate impact on relevant professional development as depicted by the lowest weighted mean (3.33) in the indicators presented. This is again attributed to the fact that faculty recognizes the impact of leadership practices in the technology initiative and utilization in terms of classroom instruction rather than professional growth.

\subsection{Relationship between the Leadership Practice and its Impact on the Implementation and Utilization of Technology Initiative}

The relationship between leadership practice and Its Impact on the Implementation and utilization of Technology Initiative has no significant statistical relationship was found between the leadership practices and the impacts to implementation of technology initiative and its utilization was found as indicated by a negative Pearson correlation coefficient of -0.059 and a p-value of 0.849 . This means that the present impact of the utilization of the technology initiative at this point in time in FEUNRMF is not influenced by the evident leadership practices of the Deans.

Though it can be inferred that there is evident leadership practice among the Deans in terms of the technology initiative implementation and utilization as presented in section 2 of this chapter and the perceived impact as presented in section 3 of this paper is also high, there was no sufficient statistical evidence to prove that the evident leadership practices impacts the implementation of the technology initiative and utilization in FEU-NRMF. This is due to the fact that both Deans and Faculty have their own embedded leadership practice in accordance to their work. Deans, on this for instance, cannot focus on technology initiative and utilization alone since this is just one area that they need to balance in order to meet the schools goal, mission and vision. Schools may find themselves stuck in a series of initial implementation efforts, trying one thing after another, but not actually achieving full implementation of a program due to its diversity [4].

\subsection{Proposed FEU-NRMF Sustainable Leadership and Instructional Framework}

The importance of technology particularly in higher educational institution cannot be overstated. Different researches have shown that a school equipped with advanced and most sophisticated technology equipment has become a major attraction to students. Thus, technology serves as potential instrument in driving educational transformation.

In a private educational institution like FEU-NRMF, the quality of education and contentment of stakeholders particularly the students and the parents are of utmost importance. A private school would not survive and eventually would lead to closure if students were displeased with the services they received.

Since leadership practices on technology initiatives were the main focus of this study, the researcher utilized the findings to construct a sustainable leadership and instructional framework. Furthermore, the framework would also help the educational leaders in guiding all their decisions related to technology.

Structure of Sustainable Leadership and Instructional Framework.

The conceptual framework was formulated for the purpose of guiding the FEU-NRMF administrators in planning, administering, supervising, evaluating, and decision-making on issues related to technology. The policy direction was in line with the school's vision of providing excellent health care services and mission of developing competent and compassionate professionals through innovative and effective use of technology.

The technology framework focused on the five interdependent areas that were formulated based on the results of the Technology Needs Assessment given to the respondents of this study. The areas of concern include student-centered learning and instruction, organizational condition, research, innovation and planning, professional development quality, vision and shared leadership, and infrastructure.

Each of the five technology areas contains a rationale that justifies reasons for a certain proposal. It was also considered 
adequately descriptive in order to expound the intended activity.

The expected outcomes were also indicated in each technology area. These were also considered as targets need to be accomplished based from the results of this study.
At the end of the plan is the set of actions that the administrators may initiate in order to strengthen the technology programs in general and achieve the indicated targets in particular.

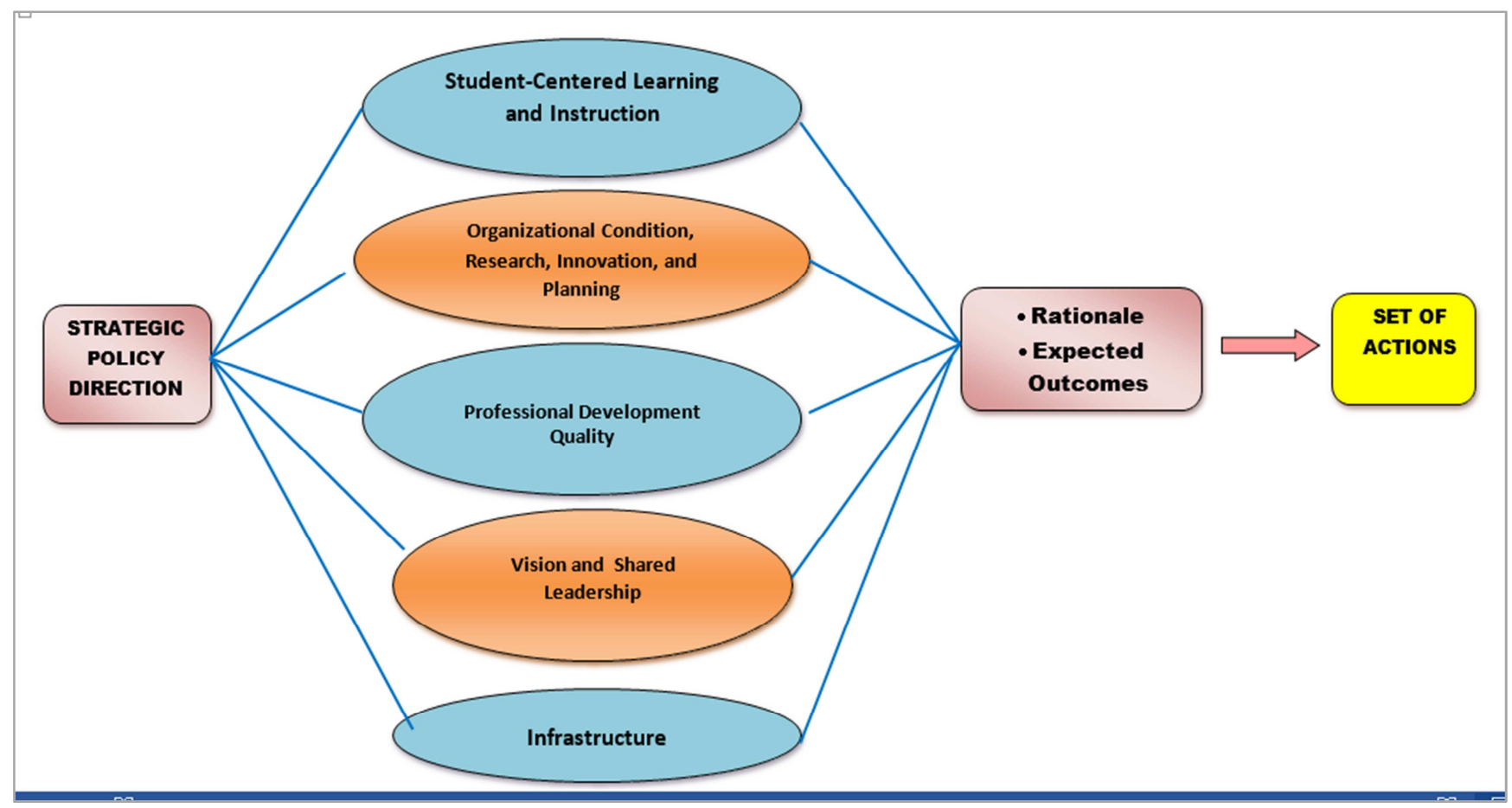

Figure 2. Sustainable leadership and instructional framework.

\section{Summary of Findings}

Based on the above stated findings, the following conclusions were drawn:

1. There is no significant difference in the present level of technology initiative and utilization of the allied programs in medicine as perceived by faculty and students. Both groups received almost equal level of technology initiative and utilization in terms of the areas assessed.

2. There is no significant relationship between the leadership practices and its impact on the utilization and implementation of technology initiative. The present impact of the utilization of technology initiative at this point in time at FEU-NRMF is not influenced by evident leadership practices of the deans of different colleges.

3. There was a high level of satisfaction received by both teachers and students as to the status of technology initiatives and utilization of the allied programs in medicine at FEU-NRMF. Stakeholders in terms of the administrators' practices and programs related to technology also gave a strong gesture of support.

4. The administrators' leadership focus on relevant, timely, and regular professional development of teachers that are anchored on the school's vision/mission may lead to upliftment of the school's academic standard in general and enhancement of students' learning in particular.

5. Educational leaders' investment on human and technological resources may increase the school's chance of gaining stakeholders' support that may eventually lead to increase in enrolment. Students who are satisfied with the technological services being provided by the school may serve as its campaign arm to encourage more enrollees in the future.

\section{Conclusions}

Based on the above stated findings, the following conclusions were drawn:

1. There is no significant difference in the present level of technology initiative and utilization of the allied programs in medicine as perceived by faculty and students. Both groups received almost equal level of technology initiative and utilization in terms of the areas assessed.

2. There is no significant relationship between the leadership practices and its impact on the utilization and implementation of technology initiative. The present impact of the utilization of technology initiative at this point in time at FEU-NRMF is not influenced by evident leadership practices of the deans of different 
colleges.

3. There was a high level of satisfaction received by both teachers and students as to the status of technology initiatives and utilization of the allied programs in medicine at FEU-NRMF. A strong gesture of support was also given by stakeholders in terms of the administrators' practices and programs related to technology.

4. The administrators' leadership focus on relevant, timely, and regular professional development of teachers that are anchored on the school's vision/mission may lead to uplift of the school's academic standard in general and enhancement of students' learning in particular.

5. Educational leaders' investment on human and technological resources may increase the school's chance of gaining stakeholders' support that may eventually lead to increase in enrolment. Students who are satisfied with the technological services being provided by the school may serve as its campaign arm to encourage more enrollees in the future.

\section{Recommendations}

Based from the study conducted, here are the following recommendations.

1. Area on organizational condition must be enhanced by formulating a specific, measurable, attainable, resultoriented, and time bounded (SMART) technology plan encompassing all the allied medical programs for the benefit of all the FEU-NRMF stakeholders.

2. Provision for budget of technology infrastructure, which includes, computer hardware/software, reliable and high-speed internet connections, and other technology equipment should be considered by the school leaders in order to adapt to the fast changing trends in the $21^{\text {st }}$ education.

3. A periodic faculty development program focusing on technology-enhanced instruction should be intensified in order for the teachers to maximize the use of technology in delivering instruction for the benefits of the students and for their professional development.

4. Because of the limitations of this study, the following are hereby proposed for further research:

(1) Replication of this study may be conducted in other private colleges and universities to determine the consistency of findings.

(2) Impact of Instructional Technology to the Performance of Students of Allied Courses in Medicine.

(3) Teachers' Perceptions of Media Education in
Selected Private Medical Colleges and Universities: Challenges and Possibilities.

(4) Mentoring and Information and Communication Technologies in Teacher Education: Basis for Designing School Technology Enhancement Program.

\section{References}

[1] Fullan, M. (2001). Leading in a culture of change: being effective in complex times. Jossey-Bass: CA.

[2] Zur, O. \& Zur, A. (2011): On Digital Immigrants and Digital Natives: How the Digital Divide Affects Families, Educational Institutions, and the Workplace. Zur Institute Online Publication. Retrieved on November 2018 from http://www.zurinstitute.com/digital_divide.html.

[3] DeNisi, A. 2015. Some further thoughts on the entrepreneurial personality. Entrep. Theory Pract. 39 997-1003. In Muñoz, R., Sánchez de Pablo, J., Peña, I., Salinero, Y. (2016). The effects of technology entrepreneurship on customers and society: a case study of a Spanish Pharmaceutical Distribution Company. Retrieved from https://www.ncbi.nlm.nih.gov/pmc/articles/PMC4923257/.

[4] Prensky, M. (2001b) Digital Natives, Digital Immigrants, Part II: Do they really think differently? On the Horizon, 9(6), 1-6. http://dx.doi.org/10.1108/10748120110424843.

[5] Binz, C., Truffer, B., \& Coenen, L. (2014). Why space matters in technological innovation systems-Mapping global knowledge dynamics of membrane bioreactor technology. Research Policy, 43, 1, 138-155. https://doi.org/10.1016/j.respol.2013.07.002.

[6] Wang, E., Myers, M. \& Sundaram, D. (2012). "DIGITAL NATIVES AND DIGITAL IMMIGRANTS: TOWARDS A MODEL OF DIGITAL FLUENCY". ECIS Proceedings. Paper 39. http://aisel.aisnet.org/ecis2012/39.

[7] Harris, D. 92012). Digital Natives Revisited: Developing digital wisdom in the modern university. SAGE journals https://doi.org/10.2304/elea.2012.9.2.173.

[8] Ockwell, D., Sagar, A., \& de Coninck, H. (2015). Collaborative research and development (R\&D) for climate technology transfer and uptake in developing counties: towards a needs driven approach. Springer Link, 131,3, 401-415. Retrieved from https://link.springer.com/article/10.1007/s10584-014-1123-2.

[9] Anadon, L., Chan, G., Harley, A., Matus, K., Moon, S., Murthy, S., \& Clark, W. (2016). Making technological innovation work for sustainable development. PNAS Proceedings of the National Academy of Sciences of the United States of America. https://doi.org/10.1073/pnas.1525004113.

[10] Hargittai, E., Fullerton, L., Menchen-Trevino, E., \& Thomas, K. (2010). Trust online: Young adults' evaluation of web content. International Journal of Communication, 4, 468-494. 